\title{
Weekend effect: complex metric for a complex pathway
}

\author{
Julian Bion
}

\section{Correspondence to}

Professor Julian Bion, Intensive Care Medicine, University of Birmingham, Birmingham B15 2TH, UK; J.F.Bion@bham.ac.uk

Accepted 16 December 2019 Published Online First 24 December 2019

\section{Sinked}

- http://dx.doi.org/10.1136/ bmjqs-2019-010067

\section{Check for updates}

(c) Author(s) (or their employer(s)) 2020. No commercial re-use. See rights and permissions. Published by BMJ.

To cite: Bion J. BMJ Qual Saf 2020;29:525-527.
'Time is tissue' has become a mantra in emergency care: delays in treatment limit the opportunity to minimise damage caused by trauma and ischaemia, particularly for conditions like acute stroke or myocardial infarction where drugs and techniques can restore blood flow. The therapeutic time window may have widened for some forms of acute ischaemic stroke, ${ }^{12}$ but that does not mean that time is no longer critical. For ST-segment elevation myocardial infarction (STEMI), survival rates are higher if balloon angioplasty is performed earlier than $90 \mathrm{~min}$ from hospital presentation. ${ }^{3}{ }^{4}$ Efforts to improve patient outcomes further by reducing time to treatment have taken a 'whole pathway' approach, from initial symptoms in the community to definitive intervention in the hospital. These have included raising public awareness, ${ }^{5}$ evaluating different routes of urgent referral to hospital ${ }^{6}$ and investigating the timing of admission to the hospital. There is now an extensive, but contradictory, literature on the impact of 'off-hours' admission on care processes in patients with a STEMI. A systematic review in $2014^{7}$ reported a higher mortality and longer door-to-balloon times for weekend admissions, while a 2017 review $^{8}$ found neither. A recent analysis of 4590 patients between 2005 and 2016 in the multicentre Melbourne registry ${ }^{9}$ has reported longer door-to-balloon times for weekend admissions (median $83 \mathrm{~min}$ vs $60 \mathrm{~min}$ weekday), but a similar case mix and no difference in outcomes. What are we to make of these results?

In this issue of BMJ Quality \& Safety, Jayawardana and colleagues ${ }^{10}$ have examined the relationship between admission timing (nights and weekends vs weekday days), hospital and 30-day postadmission mortality rates, and door-to-balloon times for 42677 patients with ST-elevation myocardial infarction whose details were available in a national clinical registry of patients with acute coronary syndromes presenting to hospitals in England and Wales between 2007 and 2012. They adjusted for severity of illness using the validated adjusted mini-Global Registry of Acute Coronary Events (GRACE) risk score, ${ }^{11}$ which includes acute physiology, troponin, creatinine and diuretic use. The authors find no difference in unadjusted outcomes between in-hours and off-hours admissions (30 day mortality rates $3.91 \%$ vs $3.86 \%$ ). However, they identify a higher GRACE score for the in-hours admissions, indicating that these patients were sicker, and when they adjust outcomes for severity, this reveals a higher than expected mortality rate in the off-hours population. Median doorto-balloon times were also $7 \mathrm{~min}$ longer in the off-hours population (45 $\mathrm{min}$ vs $38 \mathrm{~min}$ ), and longer door-to-balloon times were associated with an increased mortality risk. Incorporating time to intervention in the model attenuated the mortality difference by $38 \%$.

This is an interesting inversion of the finding by several other groups that the higher mortality observed on weekends (the so-called weekend effect) reflects increased severity of illness among patients seeking care on weekends. ${ }^{12-15}$ In other words, these studies have suggested that increased hospital mortality on weekends results from increases in risk of bad outcomes (ie, having sicker patients), not delays in care due to inadequate staffing or other quality problems potentially present on weekends. By contrast, Dr Jayawardana and colleagues report their out-of-hours population as having lower risk of death, slightly younger and with lower incidence of stroke or cerebrovascular disease and chronic renal failure. Yet, the authors find no difference in crude mortality when, according to their baseline risk factors, the mortality rate on 
weekends should have been lower because the out-ofhours admissions were less severely ill.

The authors conclude that the higher-than-expected mortality in the off-hours admissions may in part be attributed to the delay in coronary intervention. There are perhaps two additional comments to make. The first is that their UK centres' door-to-balloon times were commendably short, whether in-hours or outof-hours. The second is that they had to exclude from analysis 20234 patients from whom complete GRACE data were unavailable, and although the doorto-balloon time and the mortality in this excluded population were in the same direction as those with complete GRACE scores, the magnitude of the differences was larger in the non-GRACE off-hours population, suggesting that the absence of these data might not be a random event.

The weekend effect was first described by Bell and Redelmeier in $2001,{ }^{16}$ who reported a significantly higher weekend admission mortality rate for 23 of 100 leading causes of death in Canada. It is a complex metric, a ratio of two ratios or rates: the mortality rate for weekend admissions divided by the mortality rate for weekday admissions. It therefore has two numerators and two denominators at work, each of which can be influenced by different factors in the causal pathway. The majority of publications on this topic have quantified the magnitude of the weekend effect. A recent systematic review identified more than 600 studies, of which 68 analysed outcomes for 640 million unselected emergency and elective weekend admissions to the hospital: the pooled excess relative risk of death for weekend admissions was $16 \% .{ }^{17}$ However, very few examine causation, and the study by Jayawardana et al therefore contributes usefully to this scanty literature. In the perceptive accompanying editorial to Bell and Redelmeier's publication, Halm and Chassin ${ }^{18}$ stated that 'Disentangling the potential causal pathways would require painstaking detective work... of first accounting for the biologic and social determinants of risk and then identifying the precise differences in processes of clinical care that explain the differences in risk-adjusted outcomes'.

This 'painstaking work' has started. A detailed caserecord review study comparing quality of care and outcomes for patients in two epochs, before (20122013) and after (2016-2017) health policy changes to promote 7 -day services, ${ }^{19}$ will appear shortly. However, we already know that there does not appear to be a relationship between weekend consultant staffing and outcomes ${ }^{20}$ or 7 -day service standards, ${ }^{21}$ that weekend admissions tend to be more acutely ill, ${ }^{12-15}$ that fewer patients are admitted at weekends despite the same numbers of patients attending hospital emergency departments ${ }^{12} 22$ and that there is a marked reduction in the proportion of patients referred to hospital by their general practitioners. ${ }^{12} 22$ The search for the cause of the weekend effect clearly needs to include community services, but Jayawardana and colleagues provide a timely reminder that it is the whole patient pathway which is of interest, not just isolated segments.

Funding The authors have not declared a specific grant for this research from any funding agency in the public, commercial or not-for-profit sectors.

Competing interests None declared.

Patient consent for publication Not required.

Provenance and peer review Commissioned; internally peer reviewed.

\section{REFERENCES}

1 Goyal M, Menon BK, van Zwam WH, et al. Endovascular thrombectomy after large-vessel ischaemic stroke: a metaanalysis of individual patient data from five randomised trials. Lancet 2016;387:1723-31.

2 Powers WJ, Rabinstein AA, Ackerson T, et al. 2018 guidelines for the early management of patients with acute ischemic stroke: a guideline for healthcare professionals from the American heart Association/American stroke association. Stroke 2018;49:e46-110.

3 Park J, Choi KH, Lee JM, et al. Prognostic implications of door-to-balloon time and Onset-to-Door time on mortality in patients with ST -Segment-Elevation myocardial infarction treated with primary percutaneous coronary intervention. J Am Heart Assoc 2019;8:e012188.

4 Foo CY, Bonsu KO, Nallamothu BK, et al. Coronary intervention door-to-balloon time and outcomes in STelevation myocardial infarction: a meta-analysis. Heart 2018;104:1362-9.

5 Bray JE, Stub D, Ngu P, et al. Mass Media Campaigns' Influence on Prehospital Behavior for Acute Coronary Syndromes: An Evaluation of the Australian Heart Foundation's Warning Signs Campaign. J Am Heart Assoc 2015;4:e001927.

6 Thylén I, Ericsson M, Hellström Ängerud K, et al. First medical contact in patients with STEMI and its impact on time to diagnosis; an explorative cross-sectional study. BMJ Open 2015;5:e07059.

7 Sorita A, Ahmed A, Starr SR, et al. Off-hour presentation and outcomes in patients with acute myocardial infarction: systematic review and meta-analysis. BMJ 2014;348:f7393.

8 Enezate TH, Omran J, Al-Dadah AS, et al. Comparison of outcomes of ST-elevation myocardial infarction treated by percutaneous coronary intervention during off-hours versus On-Hours. Am J Cardiol 2017;120:1742-54.

9 Biswas S, Brennan A, Duffy SJ, et al. The impact of outof-hours presentation on clinical outcomes in ST-elevation myocardial infarction. Heart Lung Circ 2019:31320-4.

10 Jayawardana S, Salas-Vega S, Cornehl F, et al. The relationship between off-hours admissions for primary percutaneous coronary intervention, door-to-balloon time and mortality for patients with ST-elevation myocardial infarction in England: a registry-based prospective national cohort study. BMJ Qual Saf 2020;29:541-9.

11 Simms AD, Reynolds S, Pieper K, et al. Evaluation of the NICE mini-GRACE risk scores for acute myocardial infarction using the myocardial ischaemia national audit project (MINAP) 2003-2009: National Institute for cardiovascular outcomes research (NICOR). Heart 2013;99:35-40. 
12 Sun J, Girling AJ, Aldridge C, et al. Sicker patients account for the weekend mortality effect among adult emergency admissions to a large Hospital trust. BMJ Qual Saf 2019;28:223-30.

13 Mohammed M, Faisal M, Richardson D, et al. Impact of the level of sickness on higher mortality in emergency medical admissions to hospital at weekends. J Health Serv Res Policy 2017;22:236-42.

14 Walker AS, Mason A, Quan TP, et al. Mortality risks associated with emergency admissions during weekends and public holidays: an analysis of electronic health records. Lancet 2017;390:62-72.

15 Mikulich O, Callaly E, Bennett K, et al. The increased mortality associated with a weekend emergency admission is due to increased illness severity and altered case-mix. Acute Med 2011;10:182-7.

16 Bell CM, Redelmeier DA. Mortality among patients admitted to hospitals on weekends as compared with weekdays. N Engl J Med 2001;345:663-8.

17 Chen Y-F, Armoiry X, Higenbottam C, et al. Magnitude and modifiers of the weekend effect in hospital admissions: a systematic review and meta-analysis. BMJ Open 2019;9:e025764.

18 Halm EA, Chassin MR. Why do hospital death rates vary? $N$ Engl J Med 2001;345:692-4.

19 Bion J, Aldridge CP, Girling A, et al. Two-epoch cross-sectional case record review protocol comparing quality of care of hospital emergency admissions at weekends versus weekdays. BMJ Open 2017;7:e018747.

20 Aldridge C, Bion J, Boyal A, et al. Weekend specialist intensity and admission mortality in acute Hospital trusts in England: a cross-sectional study. Lancet 2016;388:178-86.

21 Meacock R, Sutton M. Elevated mortality among weekend hospital admissions is not associated with adoption of seven day clinical standards. Emerg Med J 2018;35:108-13.

22 Meacock R, Anselmi L, Kristensen SR, et al. Higher mortality rates amongst emergency patients admitted to hospital at weekends reflect a lower probability of admission. J Health Serv Res Policy 2017;22:12-19. 